Article

\title{
Circular Economy in Construction and Demolition Waste Management in the Western Balkans: A Sustainability Assessment Framework
}

\author{
Ana Nadazdi * (D), Zorana Naunovic and Nenad Ivanisevic
}

Faculty of Civil Engineering, University of Belgrade, 11000 Belgrade, Serbia; znaunovic@grf.bg.ac.rs (Z.N.); nesa@grf.bg.ac.rs (N.I.)

* Correspondence: anikolic@grf.bg.ac.rs

check for

updates

Citation: Nadazdi, A.; Naunovic, Z.; Ivanisevic, N. Circular Economy in Construction and Demolition Waste Management in the Western Balkans: A Sustainability Assessment Framework. Sustainability 2022, 14, 871. https://doi.org/10.3390/ su14020871

Academic Editors: Anibal C.

Maury-Ramirez and Jaime A Mesa

Received: 8 December 2021

Accepted: 10 January 2022

Published: 13 January 2022

Publisher's Note: MDPI stays neutral with regard to jurisdictional claims in published maps and institutional affiliations.

Copyright: (c) 2022 by the authors. Licensee MDPI, Basel, Switzerland. This article is an open access article distributed under the terms and conditions of the Creative Commons Attribution (CC BY) license (https:/ / creativecommons.org/licenses/by/ $4.0 /)$.

\begin{abstract}
Population growth, consumerism and linear (take-make-dispose) economy models have been piling up waste for decades. The construction industry is also based primarily on linear economy models, but the good news is that most of the waste can be re-used or recycled. So far, numerous models for managing construction and demolition waste in a sustainable way have been developed, but only a few models have included circular economy approaches. The main objective of this study is to propose an integrated framework for the sustainability assessment of CDW management. Apart from the economic, environmental and social aspects of sustainability, this model also includes circular economy principles. The proposed framework is based on the integration of existing methods: bottom-up materials stock approximation; cost-benefit analysis for criteria calculation; and scenario and multi-criteria decision-making analysis for sustainability. It is suggested that the European average recovery rates should be used for future scenario development. With higher re-use and recycling rates, the potential for the circularity of the recovered waste grows. In an effort to increase circularity in the region, particular attention was devoted to customize the framework and examine its potential for use in the Western Balkan countries. The framework may also be useful in countries with immature construction and demolition waste management.
\end{abstract}

Keywords: circular economy; green deal; construction and demolition waste; quantification; waste management; recycling; re-use; material stock analysis; multi-criteria decision-making

\section{Introduction}

More than a third of the waste in Europe comes from construction and demolition activities [1]. The amounts of this type of waste generated worldwide reached 3 billion tons in 2012, with China, India and the United States as the main contributors [2]. In the same year, Europe generated 0.85 billion tons of construction and demolition waste [3]. In 2018, the data for Europe shows a steady increase in the amount of construction and demolition waste (CDW), amounting to almost 1 billion tons [3].

The typical composition of CDW highly depends on several factors. The key factors are the type of activity that generates the waste and the type of structure constructed or demolished. Depending on the type of activity, waste may come from construction activities, i.e., construction waste and from demolition activities, i.e., demolition waste. Researchers mainly agree that demolition waste constitutes a larger portion of CDW [4]. When it comes to different structures, buildings contribute the most to waste generation due to their mass construction and frequent demolition, while infrastructures are sporadically constructed and rarely demolished. Therefore, depending on the location and the common construction practice in a specific area, CDW consists of mineral waste from construction and demolition (brick, concrete, insulation, etc.), other mineral waste (gravel, rock, sand, etc.), glass and wood waste, metallic waste (ferrous and non-ferrous), soils and dredging spoils [5]. More importantly, almost all streams have a great potential for further processing (treatment). 
In the following order of priority, CDW may be re-used, recycled and incinerated [6]. However, CDW is mostly disposed in landfills or, in some cases, illegally dumped $[7,8]$. CDW is mainly considered as inert [9], although there can be a small percentage of toxic substances coming from asbestos, gypsum, coal tar and heavy metals [10]. Exposure to asbestos can occur during demolition, when asbestos fibers that are released into the air are breathed in and can cause scarring and inflammation of the lungs; this can affect breathing and lead to serious health problems [11]. Asbestos has also been classified as a known human carcinogen [12-15]. Drywall can leach toxins and release hydrogen sulfide gas in landfills while occupational exposure to coal tar increases the risk of skin cancer [16].

Processing of CDW may decrease the consumption of primary raw materials and the emission of greenhouse gases (GHG) [17]. These characteristics, alongside with the large amounts of CDW generated worldwide, were recognized by both scientists and governments. They turned this potential into strategies, action plans and legislations, based on sustainable development goals (SDG).

The most recent effort of the European Union resulted in the Circular Economy Action Plan. The first Action Plan that was published in 2015 revolved around the transition from linear to circular economy business models [18]. The transition stipulates that instead of taking primary raw materials from the environment to make different products that will be disposed as waste at the end of their use, circular economy should be oriented on the prevention of products becoming waste or prolongation of their use by employing re-use or recycling [18]. The Plan identified 54 actions designed to support SDG; goal 12.5 was defined as the "reduction of waste through prevention, reduction, recycling and reuse" and named five priority waste streams, including CDW [19]. However, apart from publication of a non-binding Protocol on how to properly manage CDW and pre-demolishing assessment guidelines, not much else was achieved in the area of CDW management [20].

The New Circular Economy Action Plan was published in 2020 and will hopefully amend this problem [21]. This new plan was designed as a part of a Green Deal initiative to make Europe the first climate neutral continent by 2050 [22]. The EU will devote at least EUR 1 trillion for this goal, out of which EUR 100 billion will go to the most affected regions [23]. As for the construction industry, the highest expectations are laid upon the specific waste reduction targets which were missing in the previous Waste Framework Directive (WFD). Although the Waste Framework Directive (WFD) set a 2020 objective for re-using, recycling or other recovery of non-hazardous fractions of CDW to a minimum of $70 \%$ by weight [6], many practitioners and researchers highlighted the need to make this target treatment specific (setting a specific re-using target, a recycling target, etc.) [23]. Apart from the specific targets and changing of product regulations to include recycled materials, the New Plan also included two new strategies: the Renovation Wave and Sustainable Built Environment Strategy [21]. While the former aims to double the energy efficient renovation rate (currently at 1\%) by 2030 [24], the Sustainable Built Environment Strategy is designed to revise construction product regulations, reconsider waste regulations and promote circular economy principles.

So, what has Europe done so far to increase circularity in the construction and demolition sector? For instance, the latest data for the year 2018 shows that in the EU, mineral and non-hazardous CDW is very much recovered (in many counties is around $90 \%$ ), and that the WDF target is already achieved. In the Western Balkans, four out of eight countries have reported that they achieved the 70\% recovery target from the WFD. Two countries, Slovenia and Croatia, are EU members and as such are guided by the WFD; they reported a $98 \%$ and a $78 \%$ CDW recovery rate, respectively. Serbia and North Macedonia, as EU candidate countries, reported a CDW recovery of $81 \%$ and $100 \%$, respectively [25]. However, these high percentages may be misleading as no information is provided on whether the recovered materials were further used in high-grade or low-grade applications such as backfilling. This is due to different interpretations of the terms recycling and backfilling in EU Member States as backfilled CDW is often reported as recycled [1]. For example, the Netherlands reported an almost $100 \%$ recovery rate for CDW in 2018; the fact is that 
only around 3\% of the CDW was used in new concrete production [26] and not all CDW was recovered for high-grade applications. The lack of confidence in the quality of the recycled materials, due to a lack of quality standards, is the most cited reason for low levels of high-grade applications $[27,28]$. The other barriers for adopting the circular economy approach in CDW management practices identified by the academia are undeveloped markets for the recovered materials and the low prices of raw materials [29].

Therefore, what are the exact elements that CDW management practices should include to facilitate the future needs of circular economy in construction? What type of a sustainability assessment framework may be implemented to evaluate different management scenarios and find the optimal one? Why should the Western Balkans be in the focus and what is the circular economy perspective in the construction and demolition sector in these countries? This paper will suggest a framework that may answer these questions and facilitate these needs. It will take into account the particularities of a country and its economies and the best practices currently available in Europe to design a methodology for the assessment of CDW management options from the economic, environmental and social perspective.

To address the above questions, the current state-of-the art in the CDW management domain had to be analyzed. Desktop research was conducted in two directions. This included a review of CDW management publications in the most significant scientific journals, relevant EU policies and technical papers published in the last 15 years (from 2005). The first direction was to identify and analyze the existing sustainability assessment studies in order to identify their main elements, properties and techniques used for the assessments. This scientific review also helped to highlight the research gap that the proposed framework needed to fill. The second direction was to search for current best management practices and relevant policies that promote sustainable waste management and circular economy principles in the built environment in order to design better CDW management scenarios.

\section{Previous Studies on Sustainability Assessments of CDW Management}

The scientific community has been focused on CDW management for decades. The most recent studies (from 2011 to 2021) observed and analyzed CDW management from different aspects. The most analyzed were policies and circular economy strategies [30,31], opportunities and barriers in adopting circular economy in the built environment $[32,33]$, stakeholders' awareness [34,35], comparison of different management practices $[9,36,37]$ and application of information technologies, such as GIS and big data in CDW management [38-41].

When it comes to the sustainability assessment, the studies mostly focused on environmental and economic effects and to a lesser extent on the social effects of different treatment options and scenarios for different waste streams. A large number of studies, as expected, covered the environmental performance of recycling [42-44], recycling and landfilling [45,46] and in some cases the reduction of CDW [47]. The second most investigated aspect of CDW management that was analyzed either as a stand-alone element $[48,49]$ or in combination with the environmental [50-52] or social aspects [53] was the economic aspect.

To the best of the authors' knowledge, the first paper that suggested an integration of all three sustainability pillars in waste management systems was written by Taelman et al. in 2020 [54]. In addition to an assessment framework, they developed a set of impact categories and indicators to address both the global and local impacts of a waste management system in five areas (prosperity, human well-being, human and ecosystem health and national resources).

The first to apply this framework in the CDW management sector was Iodice et al. in 2021 [55]. They analyzed and assessed the sustainability of three CDW management scenarios (baseline, linear and best practice) in the Campania region in Italy. Sustainability was assessed from the economic, environmental and social aspects and treatment options that were considered were mobile and stationary recycling and landfilling. The results showed 
that the implementation of the best practice scenario that includes selective demolition and increased recycling may benefit both the environment and society.

Although rich in sustainability factors, as 20 factors from all three domains were observed, the study by Iodice et al. was limited just to two treatment options [55]. The other limitation concerned the data on CDW generation and composition, particularly the CDW material breakdown. Namely, the data for the waste from traditional demolition were taken from the available studies and local environmental agencies while the waste data from the selective demolition were based on assumptions and best-guess estimates.

It appears that the majority of the above-mentioned sustainability assessment studies based their calculations on the statistical records of CDW quantities or estimations from practitioners and academia. However, CDW statistics in most countries are underdeveloped or vague. Additionally, academia and practitioners base their estimations on the amount of total construction and demolition waste per GDP or capita (population). In both cases there are no reliable data on the quantities of particular waste streams such as the mineral, metallic, glass or wood waste streams. This data would facilitate the development of more appropriate treatment strategies, designed and developed for each stream that could finally lead to better and more informed decision-making.

When it comes to different CDW streams, recycled concrete (alone or as a part of mixed (CDW) is the most analyzed material, owing it to the fact that concrete is the largest contributor in the overall quantity of CDW: however, one must not overlook the treatment potential of other materials such as brick, wood and steel.

Finally, the circular economy approach is yet to be fully adopted in these assessments as most of the studies were focused mainly on recycling and landfilling, while the preparation for re-use and energy recovery as treatment options were rarely analyzed.

The proposed framework will address these limitations. Firstly, rather than using statistical data on the total generation of CDW, or CDW generation rates obtained from previous studies or practitioners, the framework will calculate and forecast the quantities of each particular CDW stream. Secondly, these quantities will be calculated on the basis of construction material quantities built into residential buildings and they will form a unique database of material stock. Finally, the CDW management scenarios will encompass all possible treatments of CDW, from preparing for re-use to energy recovery and disposal. Additionally, the CDW management scenarios will include high re-use and recycling rates to investigate the full circular economy potential of the proposed CDW management option.

\section{Proposed Integrated Framework for Sustainability Assessment of the CDW Management}

\subsection{Sustainability Assessment Framework}

A three-stage multidisciplinary methodology for the evaluation of CDW management options' sustainability is proposed. In general, the framework is designed to transform corresponding input data that may be related to the construction and demolition practice into qualitative and quantitative output data. The transformation process shown in Figure 1 uses several analyses and methods from different scientific domains, mainly waste and project management, that are integrated into one overarching methodology for the sustainability assessment.

As stated previously, this assessment should enable more informative decisions in CDW management. To facilitate this, specific goals of this framework were to form a database of materials (i.e., Material stock database) used for the construction of buildings and consequently to estimate the potential quantity of construction and demolition waste. The former presents stage one, while the latter presents stage two of the proposed framework. 


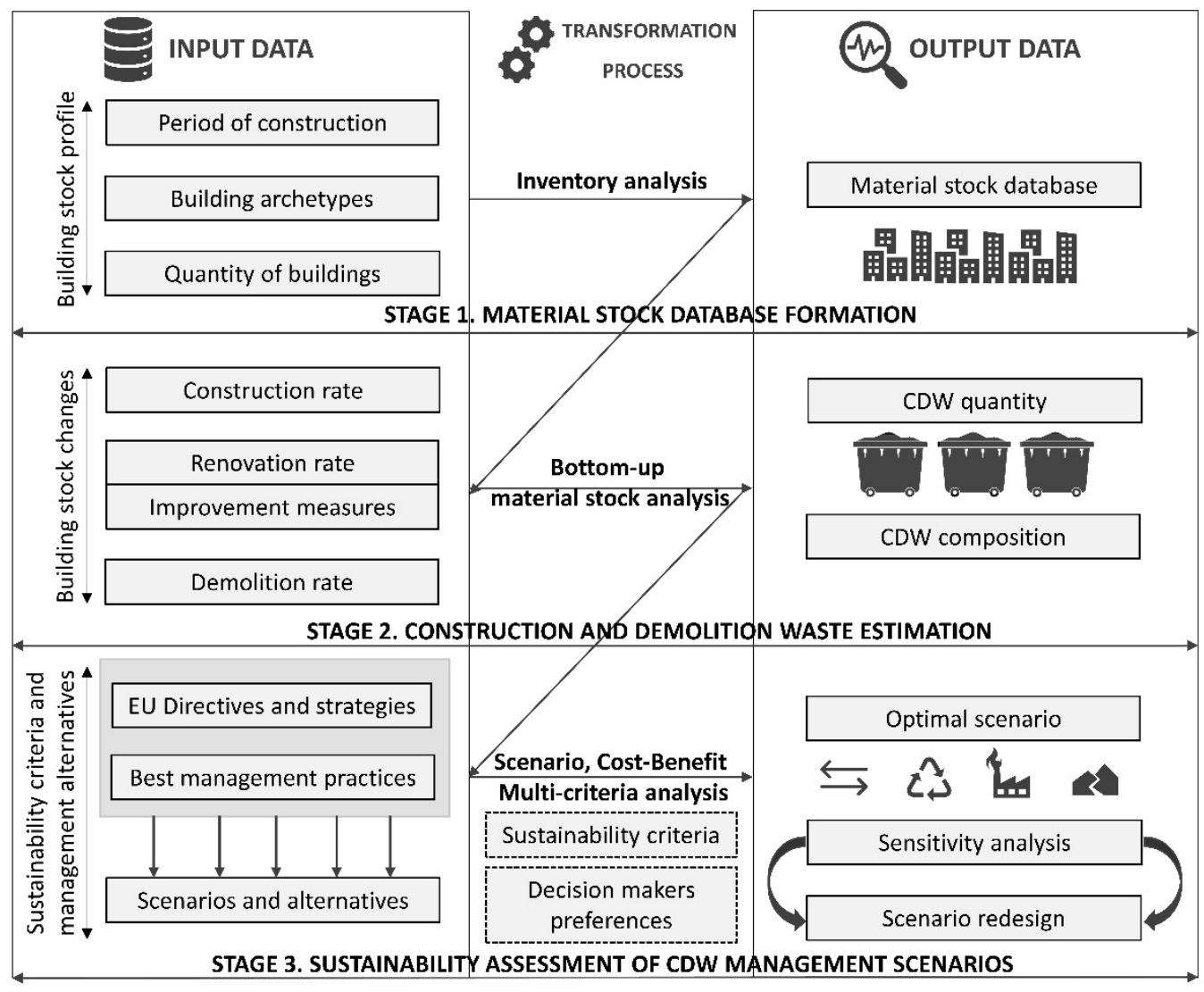

Figure 1. The framework for the sustainability assessment of CDW management scenarios.

The formation of the Material stock database requires a comprehensive set of building information, such as the type of materials built into construction elements and the physical characteristics of these elements for the entire building stock of a country. This information is rarely available. To overcome this, a bottom-up material stock analysis is suggested. The bottom-up material stock analysis includes the aggregation of the entire building environment stock into groups of objects with similar age and physical characteristics. Each group has its typical representative (archetype), which is then used further in the analysis. The transformation process in this stage of the methodology involves the segregation of archetypes into construction elements made of different materials and the calculation of their quantities. The materials are then grouped into different types (concrete, bricks, wood, metal, etc.) to facilitate the easier division of waste streams and their further treatment.

The second stage of the framework starts with the definition of the construction and demolition profile of the building stock. The building stock is a dynamic system, which means that it changes over time. Therefore, a simulation of future stock development is necessary before the quantity of CDW may be estimated. Apart from construction and demolition rates, this simulation encompasses a list of improvement measures that will be performed in the corresponding renovation cycle (usually 20 to 50 years depending on the construction element). If the projected timeframe is 50 years or more, this framework stage should also include the occurrence of natural disasters that cause significant demolition quantities, especially earthquakes in this region. Consecutively, the framework should use some method for earthquake loss estimation (including demolition quantities), similar to the one proposed in Stojadinović et al. [56]. And finally, renovation cycles serve for the definition of the building stock's renovation rates. These rates present the share of building stock from different groups of objects that will be constructed, renovated or demolished in a given year. Coupled with the material composition of the corresponding archetypes, the quantity of waste generated from these activities may be estimated. 
The final stage of the integrated methodology is to choose the optimal strategy and make the right decision with respect to different CDW management scenarios. The first step in this stage is to define the treatment rates for different waste streams and different scenarios. The sustainability of each scenario is then assessed through a set of criteria and sub-criteria that may have a positive or negative effect on the society. The authors propose a set of 16 sub-criteria grouped into three criteria (Table 1) to grasp the entire sustainability domain.

Table 1. An overview of the sustainability assessment criteria and sub-criteria.

\begin{tabular}{|c|c|c|}
\hline Economic (e) & Environmental (en) & Social (s) \\
\hline 1. Capital expenditures & & 1. Social capital expenditures \\
\hline 2. Operational expenditures & & 2. Social operational \\
\hline 3. Replacement works & 1. Avoided GHG emissions & expenditures \\
\hline 4. Clearance works & through: & 3. Social replacement works \\
\hline 5. Sale of recovered materials & recovered materials & 4. Social clearance works \\
\hline $\begin{array}{l}\text { 6. Sale of recovered energy } \\
\text { (heat and electricity) }\end{array}$ & $\begin{array}{l}\text { energy recovery } \\
\text { improved WMS }\end{array}$ & $\begin{array}{l}\text { 5. Public discomfort due to } \\
\text { landfill presence }\end{array}$ \\
\hline 7. Landfill taxes and gate fees & & 6. Arable land consumption \\
\hline 8. Residual values & & 7. Social residual values \\
\hline
\end{tabular}

The first group of criteria are costs and revenues and they belong to the economic field (labeled e in Table 1). These are capital, operational, replacement and clearance expenditures (costs) of different treatment options. The revenues from these options may come from sales of recovered product including heat and electricity and the savings from different taxes and fees, such as landfilling taxes and gate fees.

The environmental set of criteria (labeled en in Table 1) considered the positive and negative effects of different scenarios. The positive effects are reflected in decreased greenhouse gas (GHG) emissions and the reduced use of primary raw materials. There are even some treatment options that have a negative effect on society, such as landfilling and illegal dumping. Even recycling and energy recovery emit GHGs, mostly from transport and operation, but the positive effects of these waste treatment operations prevail over the negative effects.

And finally, the social set of criteria (labelled s in Table 1) includes the social adjustment of the cost and revenues to illustrate the local market imbalance with respects to taxation, customs and unemployment rates, as well as land degradation and discomfort caused by different treatment options.

To compare the scenarios with respect to these criteria and sub-criteria several multicriteria decision-making analyses are available. An application of several Multi-Criteria Decision-Making (MCDM) techniques (AHP, VIKOR, TOPSIS, etc.) can be applied as in Tirth et al. [57]. Authors propose the Analytical Hierarchy Process (AHP) to be used in this framework, due to its simplicity and flexibility. AHP was developed by Saaty in 1980 and it uses pairwise comparisons of criteria and sub-criteria and alternatives with respect to each criterion and sub-criterion in the form of matrixes of judgment. The Saaty scale [58] was used to describe the comparison: 1, 3, 5 and 9 were used to grade equal (1) to extreme (9) importance of one sub-criteria over another; 2, 4, 6 and 8 were used when compromise was needed. The matrixes of judgments are symmetrical with reciprocal values, meaning that "when activity $i$ has one value assigned when compared with activity $j$, then $j$ has the reciprocal value when compared to $i$ ".

An example of the sub-criteria comparison matrix is given in Figure 2a,b. Two Serbian waste management experts were interviewed and asked to compare pairs of sub-criteria. The experts were selected on the basis of their preferences: one that was mainly economically oriented and one that was mainly environmentally oriented. The economically oriented expert gave higher importance to the economic criteria when compared to two other criteria. For instance, a very strong (7) or even extreme importance (9) was assigned to capital expenditures (sub criteria $\left.e_{1}\right)$ over environmental $\left(e n_{1}\right)$ and social criteria $\left(s_{1}-s_{7}\right)$. 


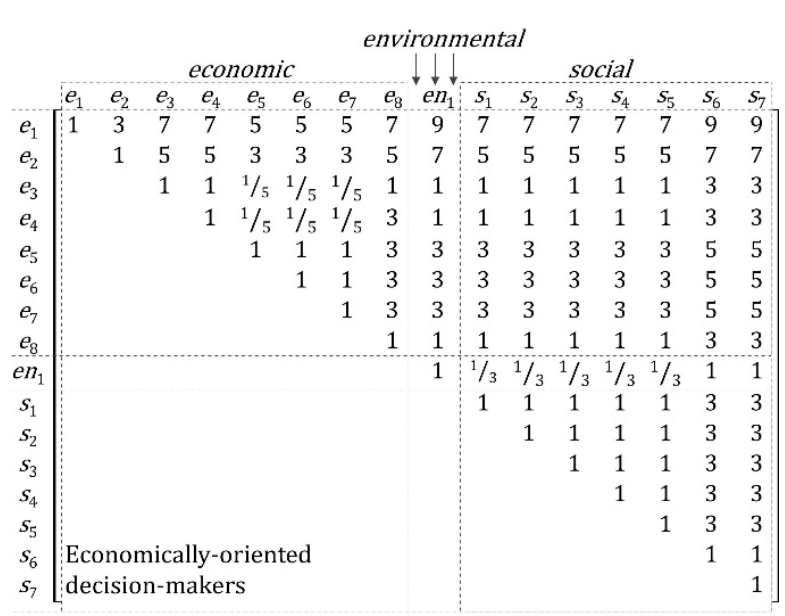

(a)

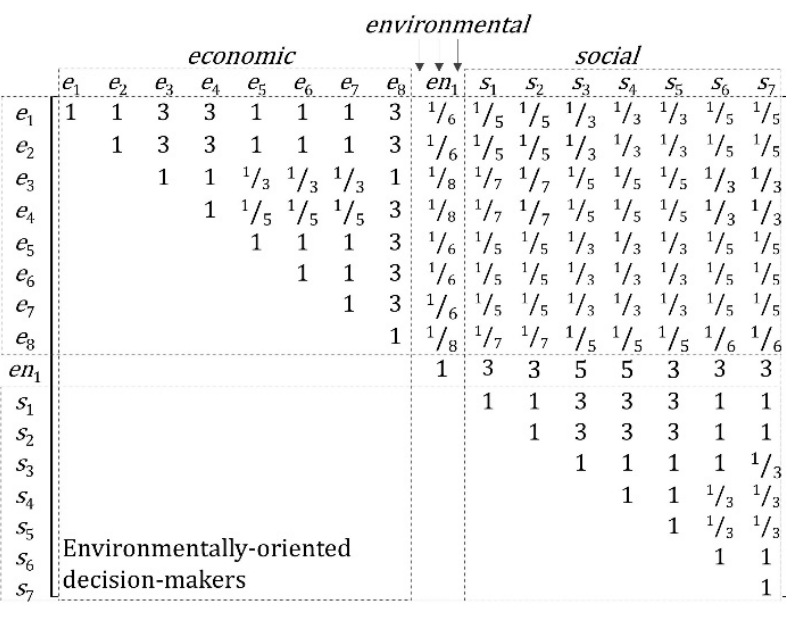

(b)

Figure 2. An example of a sub-criteria judgment matrix from Serbia: (a) Economically oriented decision-maker; (b) Environmentally oriented decision-maker.

As expected, the environmentally oriented expert preferred environmental and social criteria over economic $\left(e_{1}-e_{8}\right)$; thus, environmental criterion $e n_{1}$ had moderate importance (3) over social criteria $s_{5}$ (public discomfort due to landfill presence) and $s_{6}$ (arable land consumption), but a very strong importance $(6$, i.e., $1 / 6)$ over capital $\left(e_{1}\right)$ and operational expenditures $\left(e_{2}\right)$.

The eigenvector of each matrix is the vector of criteria priorities [58]. The CDW management strategy scenarios (alternatives) are compared with respect to each criterion and form the alternative judgment matrices. The eigen vector of these matrices is the vector of alternative priorities meaning that the alternative with the highest priority represents the optimal scenario for managing CDW.

Considering that the proposed framework serves to build a model that will illustrate a real-life CDW management system, verification and validation of whether the model is a good representation of the real-life system is advised. Both of these processes should be conducted in all three stages of the framework. The verification of a model should be carried out during the implementation process to search for errors that may hinder the implementation. The authors propose a three-step validation: the extreme conditions test; a sensitivity analysis; and the comparison of results with the real or analytical data, if real data are not available.

\subsection{CDW Management Scenarios}

To reach appropriate levels of circularity in the Western Balkan countries, one must start from different positions in each of the particular countries. The current state of CDW management differs from country to country and, for that reason, a baseline scenario for each country should be established and described before developing possible management scenarios. The future practice (or scenarios) should be established by investigating the principal policy elements that support the European best practice, mainly the economic instruments and legal requirements. Aside from the policy elements, possible scenarios should be designed on the basis of the composition of CDW and the maximum share of particular waste streams and the appropriate and available technology for their treatment.

\subsubsection{Current CDW Management Scenarios}

As shown in Figure 3, countries with larger populations and a higher GDP per capita generate more CDW, which is in line with claims from several authors [1]. Official statistical quantities of CDW for each country are given in Figure 3, with assumptions made for Albania which had no data on CDW [3]. As shown, the current generation of CDW in the 
Western Balkans is below the European average and reportedly ranges from 35.6 (North Macedonia) to 1260 kilotons (Croatia) of CDW per year. Almost 30\% of the total CDW generated belongs to the mineral fraction of CDW that is most suitable for further treatment and high-grade applications. However, these amounts are mostly underestimated as there is a significant amount of CDW waste generated and disposed of in landfills without reporting or even illegally dumped (ranging from $2.4 \%$ to $24 \%$ ) [59].

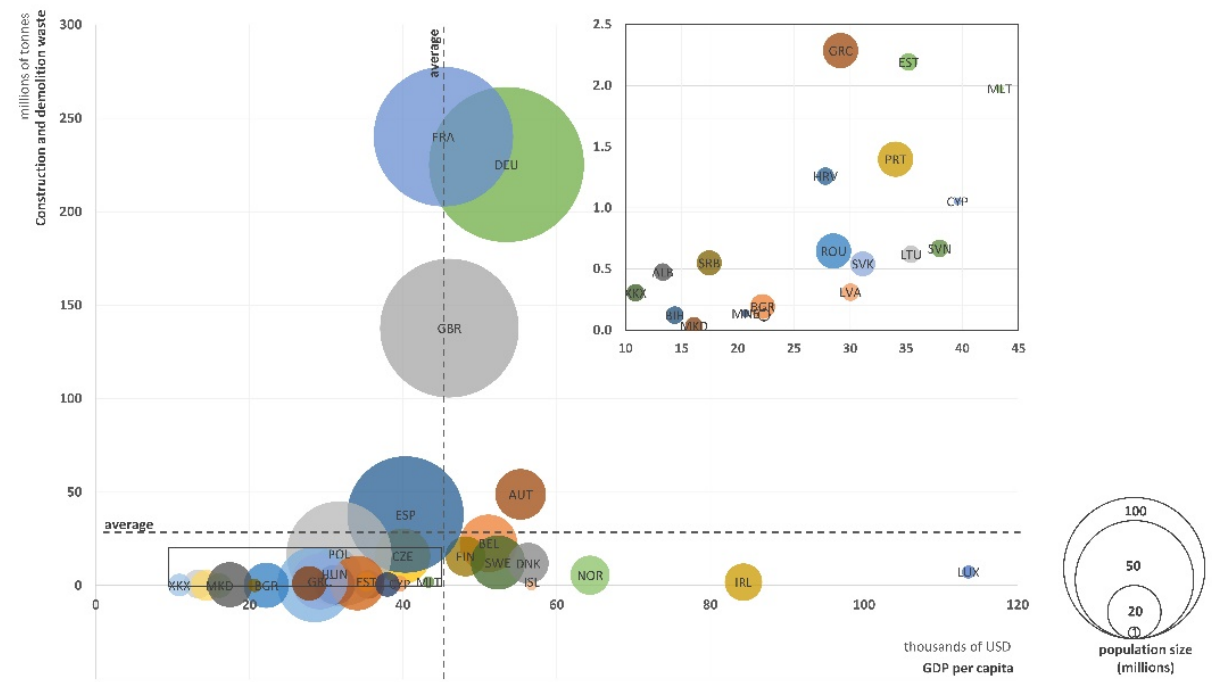

Figure 3. European CDW generation rates in relation to GPD per capita (data for 2018). (ISO-3166Aplha 3-digit codes were used for countries abbreviations).

The current treatment rates alongside with the principal elements of current CDW management are shown in Table 2. The rates are based on the national statistics published by Eurostat [25]. These numbers are most likely the result of poor management practices in the non-EU Western Balkans countries.

Table 2. Principal elements of CDW management and treatment rates in Western Balkans countries.

\begin{tabular}{|c|c|c|c|c|c|c|c|c|c|}
\hline \multirow[b]{2}{*}{ Country } & \multicolumn{6}{|c|}{ Elements of CDW Management } & \multicolumn{3}{|c|}{ Treatment Rates } \\
\hline & $\begin{array}{c}\text { End-of-Waste } \\
\text { Criteria }\end{array}$ & $\begin{array}{l}\text { Quality } \\
\text { Standards }\end{array}$ & $\begin{array}{c}\text { Recovered } \\
\text { Mat. Market }\end{array}$ & Incentives & $\begin{array}{c}\text { Bans or } \\
\text { Taxes }\end{array}$ & $\begin{array}{l}\text { Recovery } \\
\text { Targets }\end{array}$ & RC & $\mathbf{B F}$ & D \\
\hline ALB & no & & & & no & no & $\mathrm{n} / \mathrm{a}$ & $\mathrm{n} / \mathrm{a}$ & $\mathrm{n} / \mathrm{a}$ \\
\hline $\mathrm{BIH}$ & no & & & & no & no & $\mathrm{n} / \mathrm{a}$ & $\mathrm{n} / \mathrm{a}$ & $\mathrm{n} / \mathrm{a}$ \\
\hline HRV & yes & & & & foreseen & WFD & $70 \%$ & $8 \%$ & $22 \%$ \\
\hline $\mathrm{XKX} *$ & no & & & & no & no & $\mathrm{n} / \mathrm{a}$ & $\mathrm{n} / \mathrm{a}$ & $\mathrm{n} / \mathrm{a}$ \\
\hline MNE & no & no & immature & no & no & no & $0 \%$ & $0 \%$ & $100 \%$ \\
\hline MKD & no & & & & no & no & $100 \%$ & $0 \%$ & $0 \%$ \\
\hline SRB & no & & & & no & no & $0 \%$ & $81 \%$ & $19 \%$ \\
\hline SVN & yes & & & & $11(22) €$ & WFD & $98 \%$ & $0 \%$ & $2 \%$ \\
\hline
\end{tabular}

ALB-Albania; BIH—Bosnia and Herzegovina; HRV—Croatia; XKX-Kosovo; ${ }^{*}$ - under UN Resolution 1244 MNE—Montenegro; MKD—North Macedonia; SRB—Serbia; SVN—Slovenia; RC—recycling; BF—Backfilling; D—disposal (landfilling).

In most of the countries here, there is a certain legal waste framework primarily based on the Waste Directive Framework [6], however the implementation is partial. Albania, Bosnia and Hercegovina and Kosovo (under UN Resolution 1244) are yet to adopt the Circular Economy approach [59].

The EU countries, Slovenia and Croatia, have high recycling rates due to the recovery targets from the WFD. The Slovenian landfilling tax of EUR 11 and 22 per ton of nonhazardous and hazardous waste, respectively [60], may show the efficiency of tax as an 
economic instrument for increased recycling and recovery $(98 \%)$. However, the share of high-quality application of these recycled materials is still in question.

With an immature market in the rest of the countries and no quality standards that would increase confidence in the recycled materials, the recycling rates are zero. North Macedonia, with a reported recycling rate of $100 \%$ is an exception; however, as no recycling facilities were reported in North Macedonia this may be attributed to statistical misinterpretation. Clearly, there is an enormous potential for change in these rates.

\subsubsection{Future CDW Management Scenarios}

A starting point when considering the possible CDW management scenarios for the Western Balkan countries may be the average European treatment rates shown in Figure 4. The other point may be the management drivers from the countries with high recovery rates and similar GDP per capita. The data for 2018 shows that the EU average recycling and backfilling rate of the CDW mineral fraction are $83 \%$ and $7 \%$, respectively, while only $10 \%$ of the waste is disposed. This means that, on average, the EU has reached the WFD target even before 2020. When it comes to CDW management drivers, almost all EU countries have implemented either a landfill tax (ranging from EUR 5 to more than 100 per ton) or a landfill ban [60].

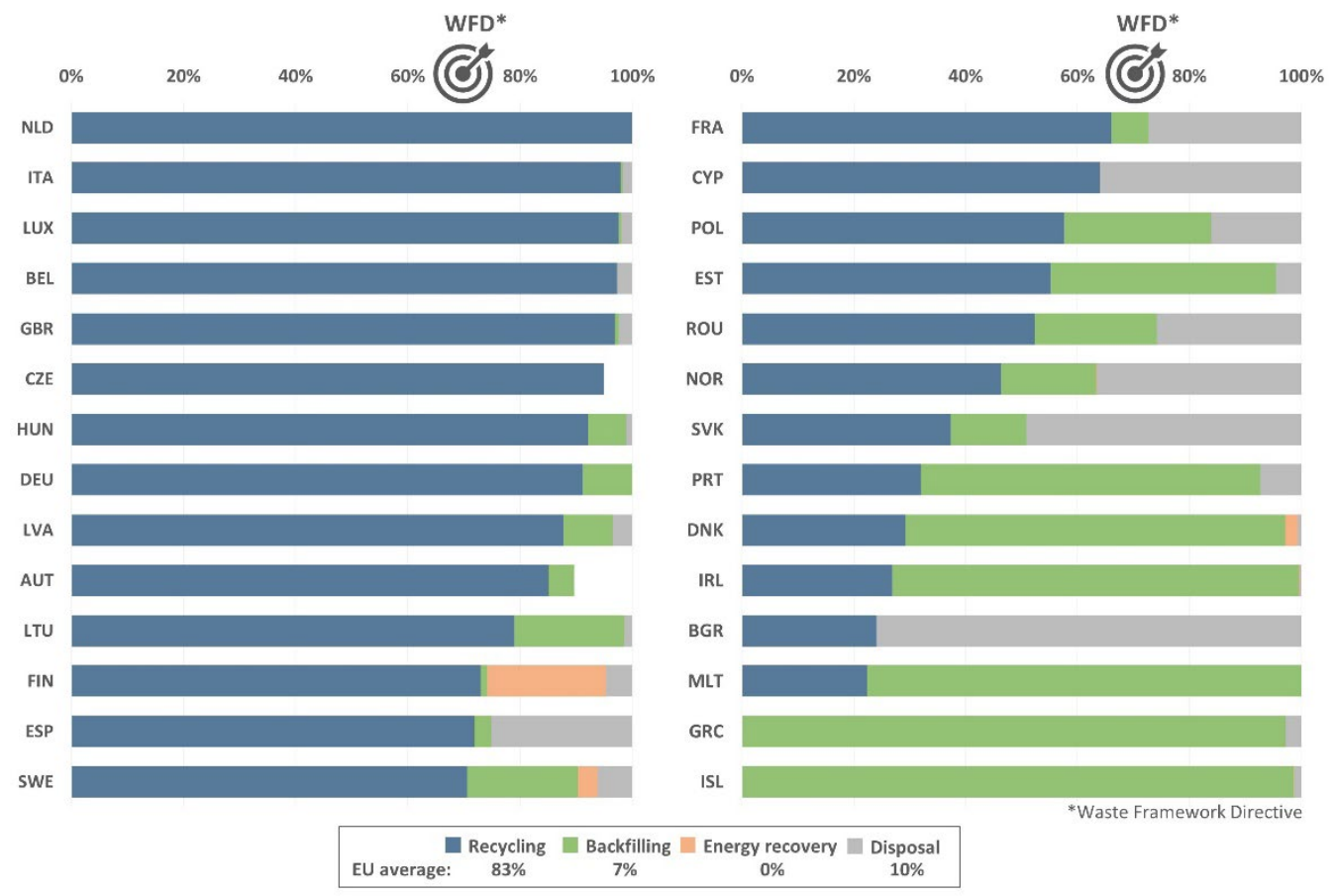

Figure 4. CDW management treatment rates in Europe (data for 2018). (ISO-3166-Aplha 3-digit codes were used for countries' abbreviations) AUT-Austria; BEL-Belgium; BGR-Bulgaria; CYPCyprus; CZE-Czech Republic; DEU—Germany; DNK—Denmark; ESP—Spain; EST_Estonia; FIN-Finland; FRA—France; GBR—Great Britain; GRC—Greece; HUN-Hungary; IRL-Ireland; ISL-Iceland; ITA—Italy; LUX_Luxemburg; LVA—Latvia; LTU—Lithuania; MLT_Malta; NLD— Netherlands; NOR—Norway; POL-Poland; PRT—Portugal; ROM-Romania; SVK—Slovakia; SWE-Sweden.

Apart from the introduction of landfill taxes, recycling in Slovenia and Croatia is further encouraged by the end-of-waste criteria developed for iron, steel, aluminum, copper and glass [61-63]. These criteria are oriented to increase the confidence of practitioners in recovered material use and increase the maturity of the recovered material market development. However, there are currently no quality standards developed specifically for the recovered materials and their use in new products. 
One of the main drivers for high recovery rates are well established and mature markets of recovered materials. For instance, valuable lessons for secondary material market development may be acquired from the Netherlands, Germany and Denmark [9] for Europe, or the United States, Australia and South Korea [64] for the rest of the world. Additionally, aside from taxes and bans, market development barriers may be successfully and more efficiently overcome by governmental subsidies or environmental credits for green building certified by BREEAM or LEAD.

Evidently, one of the possible scenarios may be to reach the European average by a prescribed period of time. On the other hand, countries that signed the Paris Agreement [65] and that are devoted to the reduction of global GHG emission should not stop there. The transition to a circular economy directly supports this goal, so scenarios based on this approach should be included in future CDW management. Apart from quality standards and end-of-waste criteria, which have been developed by the EU, the elements of these scenarios should include high re-use and high-quality recycling rates achieved through recovery thresholds at least on public projects [35] or economic instruments that would subsidize markets of recovered materials.

\subsection{Spatial and Temporal Scope of the Framework}

The authors suggest that the proposed framework should be applied to the territory of the Western Balkans for several reasons. To begin with, in addition to the EU Member States Slovenia and Croatia, these countries share a combined territory of 292.3 thousand $\mathrm{km}^{2}$ (7\% of Europe) and have almost 23.7 million inhabitants [66,67]. They also share similar architectural characteristics and construction practices, especially for the buildings built in the aftermath of World War II, when most of these countries were part of one federation (Yugoslavia). As the economies still very much lean one on another, there is also a large potential for the expansion of the recovered material market to nearby countries. Finally, most of these countries are yet to adopt circular economy principles and develop new business models to support these.

The other suggestion concerns the types of construction. Taking into account the share of residential buildings in the building stock in one country and the circumstances where infrastructure objects (bridges, tunnels, dams, etc.) are rarely renovated or demolished, the authors recommend that the framework focus should be on residential buildings.

When it comes to the time limits of the study, the authors propose that residential buildings with a higher probability that either renovation or demolition activity will occur before 2050 be used in the future case studies. These are the buildings built from 1946 to 1990, which will be aged between 50 and 94 years by 2050 and will undergo renovation in order to increase their energy efficiency. Apart from demolition, two other circumstances that may generate large amounts of CDW in the future may be frequent earthquakes or major development projects. The period prior to World War II was not considered, as it was assumed that most of the building stock in these countries was built after the war. For instance, in the case of Serbia and Bosnia and Herzegovina more than $84 \%$ and $98 \%$ of the buildings, respectively, were built after 1946 [68].

\subsection{Data Availability}

Optimal and informed decision making requires quality and reliable data. The proposed framework requires different categories of data for all three stages. These data may come from various sources (Table 3), however the authors suggest that the assessment should utilize official sets of data whenever possible. Data from the national statistic offices are easily available and the most used data in literature. This framework uses data on the quantity and type of residential buildings in a given country and their period of construction. Most of the counties gather these types of data from their censuses of population, households and dwellings, which are organized every 10 years (i.e., 2001, 2011, 2021). Considering that most of the countries delayed their censuses for a few months or even a 
year due to the COVID-19 outbreak, results from the previous censuses, held in 2011 (or 2013 in case of Bosnia and Herzegovina), are used.

Table 3. A review of the framework input data and data availability.

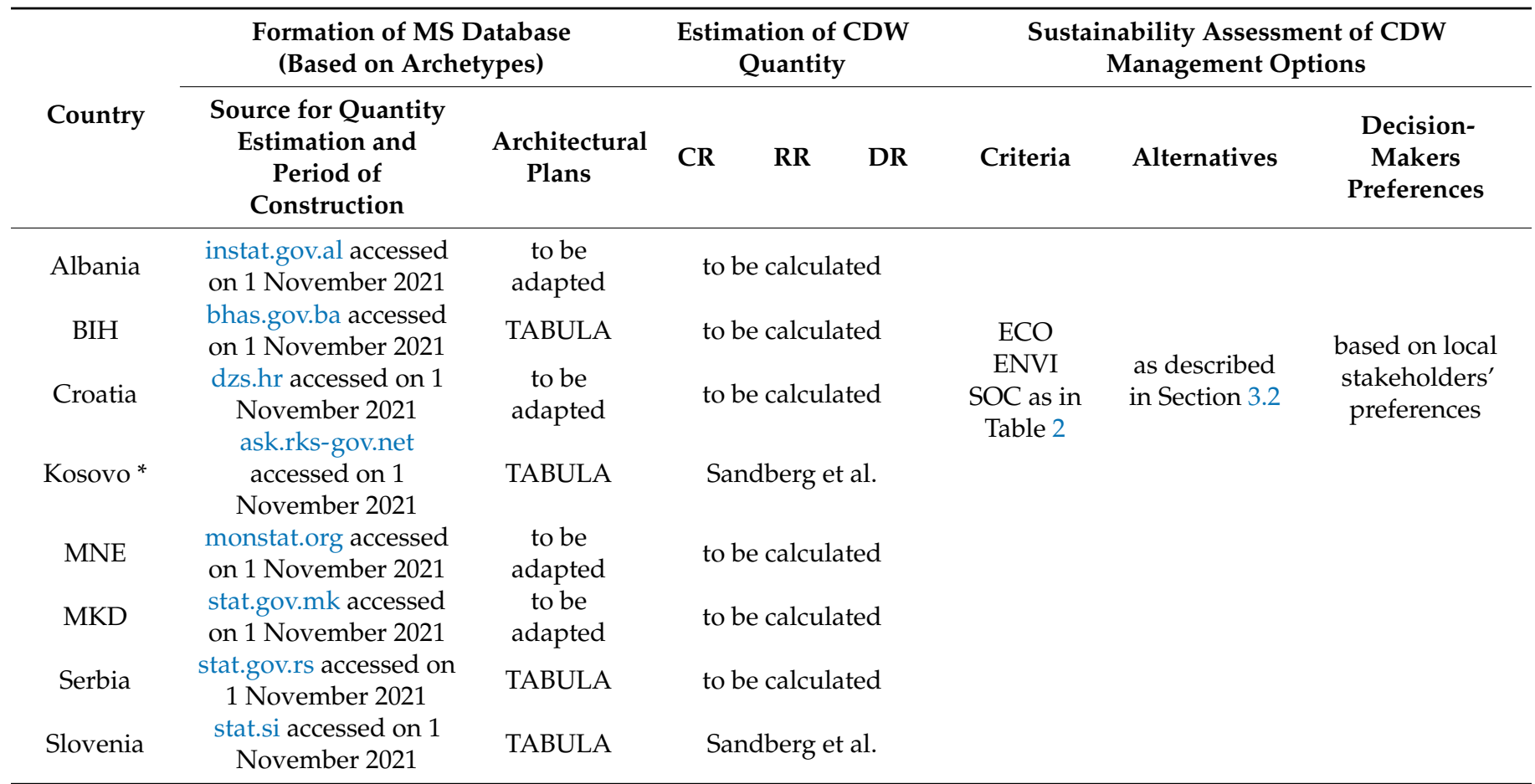

BIH-Bosnia and Herzegovina; Kosovo *-under UN Resolution 1244; MNE-Montenegro; MKD-North Macedonia; MS-Material stock; $\mathrm{CR}$ - construction rate; RR-renovation rate; DR-demolition rate; ECOEconomic; ENVI-Environmental; SOC_-Social.

The other set of data, related to the archetypes of building, the physical characteristics of their elements and the type of materials from which these elements were made, can be obtained from the direct surveying of the residential building stocks. Conveniently, 13 European countries participated in the TABULA project, which was performed from 2009 to 2013, including Bosnia and Herzegovina, Serbia and Slovenia. This project was cofounded by the European Union with the aim of developing building typologies and calculating possible energy savings by the implementing improvement measures [68]. Buildings were classified on the basis of their type and period of construction; namely, single house and multi-house buildings (including high-rise buildings) were further divided into six groups depending on the period in which they were built (for example: before 1945, 1946-1960, 1961-1970, 1971-1980, 1981-1990, 1991-2011).

In these periods, 29 archetypes were developed for Bosnia and Herzegovina, 39 for Serbia and 24 for Slovenia [68]. In the absence of better results for the other Western Balkans countries, the authors suggest that these archetypes may also serve as the starting points for Croatia, Kosovo, Montenegro and North Macedonia, especially if we analyze the building stock for the period of 1946-1990, when all of these countries were part of one federation. One may choose to use building archetypes from the adjacent regions of neighboring countries with similar economies when deciding which available archetype to use. For instance, certain archetypes from Slovenia may be used for north Croatia, or archetypes from south Serbia may be used for Kosovo, etc.

Contrary to static building stock modelling, such as a time snapshot of building stock in 2013, the second stage of the proposed framework involves dynamic stock modelling, i.e., future changes of building stocks as developed by Sandberg et al. [69]. They used information from national statistics and demolition and renovation probability to perform the simulation of the building stock in 11 European countries by 2050. The results, based 
on data from 11 countries with different construction practices, showed similar results (the renovation rate ranged from $0.6 \%$ to $1.6 \%$ while the demolition rate ranged from $0.4 \%$ to $1.2 \%)$. For Serbia and Slovenia, who participated in the Sandberg et al. study [69], the future CDW management sustainability assessments may use the direct results from this study, while other Western Balkan countries should develop their own simulations on the basis of this model.

\section{Discussion}

\subsection{Comparison with Other Sustainability Assessment Framework}

The assessment framework proposed in this study is compared with other sustainability assessments studies in the CDW management domain. Details of this comparison are provided in Table 4. As shown in Table 4, other studies most often include the comparison of two CDW treatment scenarios (mostly recycling and disposal) end evaluate only the environmental and economical aspect of sustainability, while the proposed framework encompasses all CDW treatment options (from re-use to disposal) and all sustainability aspects.

Table 4. Comparison of the proposed sustainability framework and literature data.

\begin{tabular}{|c|c|c|c|c|c|c|c|}
\hline \multirow{2}{*}{ Reference } & \multicolumn{3}{|c|}{ Scope } & \multirow{2}{*}{$\begin{array}{c}\text { Treatment } \\
\text { Options }\end{array}$} & \multicolumn{3}{|c|}{ Sustainability } \\
\hline & Level & Forecast & Waste Stream & & ECO & ENVI & SOC \\
\hline $\begin{array}{l}\text { Proposed } \\
\text { framework }\end{array}$ & NAT & $\sqrt{ }$ & $\begin{array}{l}\text { bricks, concrete, stone, } \\
\text { metal, wood, plastic, } \\
\text { gypsum, glass }\end{array}$ & $\begin{array}{c}\text { RU, RC, ER, } \\
\text { D }\end{array}$ & $\sqrt{ }$ & $\sqrt{ }$ & $\sqrt{ }$ \\
\hline [55] & REG & - & \multirow{11}{*}{$\begin{array}{c}\text { mixed CDW } \\
\text { mixed CDW, wood, plastic, } \\
\text { plasterboards, glass, metal } \\
\text { concrete } \\
\text { mineral CDW } \\
\text { concrete } \\
\text { concrete } \\
\text { gypsum, cement, concrete } \\
\text { mineral CDW, metal, wood, } \\
\text { mixed CDW } \\
\text { mixed CDW } \\
\text { mixed CDW } \\
\text { mixed CDW }\end{array}$} & $\mathrm{RC}, \mathrm{D}$ & \multirow[t]{2}{*}{$\sqrt{ }$} & $\sqrt{ }$ & \multirow[t]{4}{*}{$\sqrt{ }$} \\
\hline [44] & PRO & - & & $\mathrm{n} / \mathrm{a}$ & & $\sqrt{ }$ & \\
\hline [43] & NAT & - & & $\mathrm{RC}, \mathrm{D}$ & \multirow[t]{2}{*}{$\sqrt{ }$} & $\sqrt{ }$ & \\
\hline [46] & CIT & - & & $\mathrm{RC}, \mathrm{D}$ & & $\sqrt{ }$ & \\
\hline [53] & PRO & $\sqrt{ }$ & & $\mathrm{RC}$ & $\sqrt{ }$ & $\sqrt{ }$ & \multirow[t]{4}{*}{$\sqrt{ }$} \\
\hline [42] & PRO & - & & $\mathrm{RC}$ & & $\sqrt{ }$ & \\
\hline [52] & REG & - & & $\mathrm{RC}$ & $\sqrt{ }$ & $\sqrt{ }$ & \\
\hline [45] & NAT & $\sqrt{ }$ & & $\begin{array}{c}\text { RU, RC, ER, } \\
\text { D }\end{array}$ & $\sqrt{ }$ & $\sqrt{ }$ & \\
\hline$[48,49]$ & CIT & $\sqrt{ }$ & & $\mathrm{RC}$ & $\sqrt{ }$ & & \\
\hline$[51]$ & NAT & $\sqrt{ }$ & & $\mathrm{RC}, \mathrm{D}$ & $\sqrt{ }$ & $\sqrt{ }$ & \\
\hline [50] & REG & - & & $\mathrm{RC}, \mathrm{D}$ & $\sqrt{ }$ & $\sqrt{ }$ & $\sqrt{ }$ \\
\hline
\end{tabular}

The proposed framework also aims to include more waste streams then other studies that were mainly focused on concrete or mixed CDW stream. The information on CDW streams quantities may lead to better forecasting and more effective CDW management decisions. To facilitate this, the proposed framework integrates a bottom-up material stock analysis, rather than using practitioners' estimations or statistical data on the CDW quantities.

When it comes to the comparison of the scope of the studies, the presented framework is designed for sustainability assessments on a national level, but can easily be applied on a regional or a city level. The principles of the framework proposed here are not country specific. The framework may be used worldwide in countries that are early adopters of the circular economy approach and with no reliable statistics related to CDW management. However certain preconditions are needed. The framework relies on the (arche)type of residential buildings to determine the material stock and this has to exist in some form in the particular country. Additionally, the renovation and demolition profile and the CDW management scenarios are also country specific and are subject to the level of economic development and the legal framework within the country. 


\subsection{Limitations of the Framework}

The proposed framework has several main limitations. One of the most important is related to the material and building stock analysis. Namely, only residential buildings are included on the basis of the assumption that as a result of the Renovation Wave strategy, future activities will predominantly be the renovation of the residential building stock. For the same reason and due to their age, only typical residential buildings that will have existed for 50 or more years in 2040 are included.

Another limitation concerns the generalization of the entire residential building stock and its approximation with typical building representatives. As much as these representatives are rich in details regarding their physical and geometrical characteristics, they still cannot represent the entire stock. However, with no other reliable data on the stock, the authors believe that this is a good representation especially when it comes to construction practices, element types and materials used in a certain period. In order to cover the uncertainties in the quantity of materials and consequently the waste generated, the authors suggest that a sensitivity analysis should be conducted in each stage of the framework.

Finally, the environmental aspect of the sustainability assessment is focused around GHG emissions, $\mathrm{CO}_{2}$ emissions in particular. This was suggested in order to simplify the analysis. $\mathrm{CO}_{2}$ emissions are easily calculated and monetized. On the other hand, other emission to air such as dust, dioxins, etc. were excluded.

Furthermore, emissions to water (both surface and underground) and soil (leachate, heavy metals) were not included in the study as they are considered minimal due to the inert nature of the construction and demolition waste. However, future holistic assessments should include them as well.

\subsection{Implications for CDW Management}

The primary focus of the presented work was to create a framework that is based on sound research and that can be applied in practice and be as user friendly as possible. Further research will focus on framework validation through case studies, as a platform for benchmarking. Additional framework development implies the inclusion of more evaluation criteria, non-residential buildings, a wider temporal scope and different methods for MCDM analysis. The validation of the calculated waste quantities is expected to be done with Building Information Modeling (BIM) and Geographic Information System (GIS) modeling.

Decision-makers and practitioners can use the material stock database when planning renovation and demolition strategies in certain locations as well as when designing their business models. Both national and local governments may formulate more informative CDW management strategies based on the proposed framework that would benefit the environment and society at large.

\section{Conclusions}

The circular economy is gaining momentum worldwide, requiring that more complex and more sustainable CDW management strategies are being developed. The existing models for sustainability assessment rarely include all three aspects of sustainability (economic, environmental, social). On the other hand, almost all of the models are based on statistical records on CDW quantities that often underestimate the real CDW generation rates.

The integrated framework proposed in this work uses scenario and multi-criteria analysis that are frequently used in the decision-making process and couples them with a bottom-up material stock analysis. The framework is designed to yield three sets of results: a material stock database, the quantity of CDW and the optimal scenario for managing this CDW. Aside from the obvious use in CDW management decision-making, the authors believe that the material stock database may be a valuable resource for circular economy planning. This database scales the type and the quantity of materials built into the residential building stock. At some point this material will become waste due to renovation and demolition activity. By knowing its quantity and composition, different 
CDW management strategies with higher re-use and recycle rates may be developed that support the Circular economy. The authors propose the use of AHP for the selection of the optimal CDW management scenario. This is completed in two steps: (1) through economic, environmental and social criteria comparison on the basis of experts' preferences; and (2) scenarios (alternatives) comparison on the basis of these criteria.

Future frameworks may include non-residential buildings and cover the entire building stock as well as infrastructure objects. As well as this, a temporal boundary of future research may be extended to cover buildings built after 1990. Considering that circular economy-oriented legislation is expected in the years to come, future scenarios should analyze its impact on the society in these countries.

Considering that the sustainability assessment suggested in the framework will be the first of its kind in the Western Balkans as well as in Croatia and Slovenia, the authors believe it would be very beneficial both to governments and practitioners. Governments may use it when analyzing and deciding on the circular economy policies and strategies for CDW management at both the national and local scale, while practitioners may use it to create more sustainable and more circular business models.

Author Contributions: A.N.-conceptualization, investigation, methodology, visualization and writing - original draft preparation; Z.N.—investigation, methodology and writing-review and editing; N.I.—writing - review and editing and supervision. All authors have read and agreed to the published version of the manuscript.

Funding: This research received no external funding.

Institutional Review Board Statement: Not applicable.

Informed Consent Statement: Not applicable.

Data Availability Statement: Not applicable.

Conflicts of Interest: The authors declare no conflict of interest.

\section{References}

1. Sáez, P.V.; Osmani, M. A diagnosis of construction and demolition waste generation and recovery practice in the European Union. J. Clean. Prod. 2019, 241, 118400. [CrossRef]

2. Akhtar, A.; Sarmah, A.K. Construction and demolition waste generation and properties of recycled aggregate concrete: A global perspective. J. Clean. Prod. 2018, 186, 262-281. [CrossRef]

3. Eurostat. Generation of Waste by Waste Category, Hazardousness and NACE Rev.2 Activity. Available online: https:/ / ec.europa. eu/eurostat/databrowser/view/ENV_WASGEN\$DEFAULTVIEW/default/table (accessed on 18 October 2021).

4. Bossink, B.; Brouwers, H.J.H. Construction Waste: Quantification and Source Evaluation. J. Constr. Eng. Manag. 1996, 122, 55-60. [CrossRef]

5. Eurostat European Commission. Manual on Waste Statistics. A Handbook for Data Collection on Waste Generation and Treatment; Publication Office of the European Union: Luxembourg, 2013.

6. The European Parliament and The Council of the European Union. Directive 2008/98/EC on Waste and Repealing Certain Directives; Publication Office of the European Union: Luxembourg, 2008; pp. 312/3-312/30.

7. Wu, H.; Wang, J.; Duan, H.; Ouyang, L.; Huang, W.; Zuo, J. An innovative approach to managing demolition waste via GIS (geographic information system): A case study in Shenzhen city, China. J. Clean. Prod. 2016, 112, 494-503. [CrossRef]

8. Mihai, F.-C. Construction and Demolition Waste in Romania: The Route from Illegal Dumping to Building Materials. Sustainability 2019, 11, 3179. [CrossRef]

9. Gálvez-Martos, J.-L.; Styles, D.; Schoenberger, H.; Zeschmar-Lahl, B. Construction and demolition waste best management practice in Europe. Resour. Conserv. Recycl. 2018, 136, 166-178. [CrossRef]

10. European Commission. European Waste Catalogue; Publication Office of the European Union: Luxembourg, 2000 ; pp. 1-46.

11. Agency for Toxic Substances and Disease Registry. Health Effects of Asbestos. Available online: https://www.atsdr.cdc.gov/ asbestos/health_effects_asbestos.html (accessed on 1 December 2021).

12. Agency for Toxic Substances and Disease Registry. Toxicological Profile for Asbestos. National Toxicology Program. Asbestos. 2001. Available online: https://www.atsdr.cdc.gov/toxprofiles/tp61.pdf (accessed on 1 December 2021).

13. U.S. Department of Health and Human Services. Report on Carcinogens. Fourteenth Edition. National Toxicology Program. 2016 Available online: https://hero.epa.gov/hero/index.cfm/reference/details/reference_id/3827262 (accessed on 1 December 2021).

14. U.S. Environmental Protection Agency. Health Effects Assessment for Asbestos. EPA/540/1-86/049 (NTIS PB86134608). 1984. Available online: https:/ / bit.ly/3rchVpI (accessed on 1 December 2021). 
15. International Agency for Research on Cancer (IARC). Evaluation of Carcinogenic Risk to Humans. Arsenic, Metals, Fibres and Dusts. (IARC Monographs on the Evaluation of Carcinogenic Risks to Humans, No. 100C.). 2012. Available online: https: / / publications.iarc.fr / Book-And-Report-Series/Iarc-Monographs-On-The-Identification-Of-Carcinogenic-HazardsTo-Humans / Arsenic-Metals-Fibres-And-Dusts-2012 (accessed on 1 December 2021).

16. National Cancer Institute. Coal Tar and Coal-Tar Pitch-Cancer-Causing Substances-National Cancer Institute. Available online: https://www.cancer.gov/about-cancer/causes-prevention/risk/substances/coal-tar (accessed on 26 December 2021).

17. de Wit, M.; Ramkumar, J.H.S.; Douma, H.F.A. The Circularity Gap Report. An Analysis of the Circular State of the Global Economy. 2018. Available online: https:/ /www.circle-economy.com/news/the-circularity-gap-report-our-world-is-only-9circular\#.W09Rh9IzZPY (accessed on 1 November 2021).

18. European Commision. Clossing the Loop-An EU Action Plan for the Circular Economy, COM(2015). Brussels, 2015. Available online: https:/ / eur-lex.europa.eu/legal-content/EN/TXT/?uri=CELEX:52015DC0614 (accessed on 1 November 2021).

19. United Nations General Assembly. Transforming Our World: The 2030 Agenda for Sustainable Development; United Nations: New York, NY, USA, 2015.

20. European Commisssion. Report on the Implementation of the Circular Economy Action Plan. Brussels, 2019. Available online: https:/ / ec.europa.eu/info/publications/report-implementation-circular-economy-action-plan-1_en (accessed on 1 November 2021).

21. European Commisssion. A New Circular Economy Action Plan. For a Cleaner and More Competitive Europe. Brussels, 2020. Available online: https: / / eur-lex.europa.eu/legal-content/EN/TXT/?qid=1583933814386\&uri=COM:2020:98:FIN (accessed on 1 November 2021).

22. European Commisssion. The European Green Deal. 2019. Available online: https://eur-lex.europa.eu/legal-content/EN/TXT/ ?uri=COM\%3A2019\%3A640\%3AFIN (accessed on 1 November 2021).

23. European Commisssion. Sustainable Europe Investment Plan. European Green Deal Investment Plan. 2020. Available online: https:/ / eur-lex.europa.eu/legal-content/EN/TXT/?uri=CELEX\%3A52020DC0021 (accessed on 1 November 2021).

24. European Commisssion. A Renovation Wave for Europe-Greening Our Buildings, Creating Jobs, Improving Lives. 2020. Available online: https:/ / eur-lex.europa.eu/legal-content/EN/TXT/?uri=CELEX\%3A52020DC0662 (accessed on 1 November 2021).

25. Eurostat. Treatment of Waste by Waste Category, Hazardousness and Waste Management Operations. Available online: https: / / ec.europa.eu/eurostat/databrowser/view/ENV_WASTRT_custom_1426044/default/table (accessed on 18 October 2021).

26. Zhang, C.; Hu, M.; Yang, X.; Miranda-Xicotencatl, B.; Sprecher, B.; Di Maio, F.; Zhong, X.; Tukker, A. Upgrading construction and demolition waste management from downcycling to recycling in the Netherlands. J. Clean. Prod. 2020, 266, 121718. [CrossRef]

27. Di Maria, A.; Eyckmans, J.; Van Acker, K. Downcycling versus recycling of construction and demolition waste: Combining LCA and LCC to support sustainable policy making. Waste Manag. 2018, 75, 3-21. [CrossRef]

28. Badraddin, A.K.; Rahman, R.A.; Almutairi, S.; Esa, M. Main Challenges to Concrete Recycling in Practice. Sustainability 2021, 13, 11077. [CrossRef]

29. European Commisssion. EU Construction Sector: In Transition towards a Circular Economy. 2019. Available online: https: / / ec.europa.eu/docsroom/documents/34904 (accessed on 1 November 2021).

30. Bao, Z.; Lu, W. Developing efficient circularity for construction and demolition waste management in fast emerging economies: Lessons learned from Shenzhen, China. Sci. Total Environ. 2020, 724, 138264. [CrossRef]

31. Ruiz, L.A.L.; Ramón, X.R.; Domingo, S.G. The circular economy in the construction and demolition waste sector-A review and an integrative model approach. J. Clean. Prod. 2019, 248, 119238. [CrossRef]

32. Liu, J.; Wu, P.; Jiang, Y.; Wang, X. Explore potential barriers of applying circular economy in construction and demolition waste recycling. J. Clean. Prod. 2021, 326, 129400. [CrossRef]

33. Ratnasabapathy, S.; Alashwal, A.; Perera, S. Exploring the barriers for implementing waste trading practices in the construction industry in Australia. Built Environ. Proj. Asset Manag. 2021, 11, 559-576. [CrossRef]

34. Chen, J.; Hua, C.; Liu, C. Considerations for better construction and demolition waste management: Identifying the decision behaviors of contractors and government departments through a game theory decision-making model. J. Clean. Prod. 2018, 212, 190-199. [CrossRef]

35. Ghaffar, S.H.; Burman, M.; Braimah, N. Pathways to circular construction: An integrated management of construction and demolition waste for resource recovery. J. Clean. Prod. 2020, 244, 118710. [CrossRef]

36. Tam, V.W.-Y.; Lu, W. Construction Waste Management Profiles, Practices, and Performance: A Cross-Jurisdictional Analysis in Four Countries. Sustainability 2016, 8, 190. [CrossRef]

37. Nunes, K.; Mahler, C.F. Comparison of construction and demolition waste management between Brazil, European Union and USA. Waste Manag. Res. 2020, 38, 415-422. [CrossRef]

38. Lu, W.; Chen, X.; Peng, Y.; Shen, L. Benchmarking construction waste management performance using big data. Resour. Conserv. Recycl. 2015, 105, 49-58. [CrossRef]

39. Lu, W.; Webster, C.; Chen, K.; Zhang, X.; Chen, X. Computational Building Information Modelling for construction waste management: Moving from rhetoric to reality. Renew. Sustain. Energy Rev. 2017, 68, 587-595. [CrossRef]

40. Li, C.Z.; Zhao, Y.; Xiao, B.; Yu, B.; Tam, V.W.; Chen, Z.; Ya, Y. Research trend of the application of information technologies in construction and demolition waste management. J. Clean. Prod. 2020, 263, 121458. [CrossRef] 
41. Han, D.; Kalantari, M.; Rajabifard, A. Building Information Modeling (BIM) for Construction and Demolition Waste Management in Australia: A Research Agenda. Sustainability 2021, 13, 12983. [CrossRef]

42. Marinković, S.; Dragaš, J.; Ignjatović, I.; Tošić, N. Environmental assessment of green concretes for structural use. J. Clean. Prod. 2017, 154, 633-649. [CrossRef]

43. Mah, C.M.; Fujiwara, T.; Ho, C.S. Life cycle assessment and life cycle costing toward eco-efficiency concrete waste management in Malaysia. J. Clean. Prod. 2018, 172, 3415-3427. [CrossRef]

44. Pantini, S.; Rigamonti, L. Is selective demolition always a sustainable choice? Waste Manag. 2019, 103, 169-176. [CrossRef]

45. Dahlbo, H.; Bachér, J.; Lähtinen, K.; Jouttijärvi, T.; Suoheimo, P.; Mattila, T.; Sironen, S.; Myllymaa, T.; Saramäki, K. Construction and demolition waste management-A holistic evaluation of environmental performance. J. Clean. Prod. 2015, 107, 333-341. [CrossRef]

46. Yazdanbakhsh, A. A bi-level environmental impact assessment framework for comparing construction and demolition waste management strategies. Waste Manag. 2018, 77, 401-412. [CrossRef]

47. Ding, Z.; Zhu, M.; Tam, V.W.; Yi, G.; Tran, C. A system dynamics-based environmental benefit assessment model of construction waste reduction management at the design and construction stages. J. Clean. Prod. 2018, 176, 676-692. [CrossRef]

48. Coelho, A.; de Brito, J. Economic viability analysis of a construction and demolition waste recycling plant in Portugal-part I: Location, materials, technology and economic analysis. J. Clean. Prod. 2013, 39, 338-352. [CrossRef]

49. Coelho, A.; de Brito, J. Economic viability analysis of a construction and demolition waste recycling plant in Portugal-Part II: Economic sensitivity analysis. J. Clean. Prod. 2013, 39, 329-337. [CrossRef]

50. Coronado, M.; Dosal, E.; Coz, A.; Viguri, J.R.; Andrés, A. Estimation of Construction and Demolition Waste (C\&DW) Generation and Multicriteria Analysis of C\&DW Management Alternatives: A Case Study in Spain. Waste Biomass Valorization 2011, 2, 209-225. [CrossRef]

51. Marzouk, M.; Azab, S. Environmental and economic impact assessment of construction and demolition waste disposal using system dynamics. Resour. Conserv. Recycl. 2014, 82, 41-49. [CrossRef]

52. Silgado, S.S.; Valdiviezo, L.C.; Domingo, S.G.; Roca, X. Multi-criteria decision analysis to assess the environmental and economic performance of using recycled gypsum cement and recycled aggregate to produce concrete: The case of Catalonia (Spain). Resour. Conserv. Recycl. 2018, 133, 120-131. [CrossRef]

53. Wijayasundara, M.; Mendis, P.; Crawford, R.H. Integrated assessment of the use of recycled concrete aggregate replacing natural aggregate in structural concrete. J. Clean. Prod. 2018, 174, 591-604. [CrossRef]

54. Taelman, S.; Sanjuan-Delmás, D.; Tonini, D.; Dewulf, J. An operational framework for sustainability assessment including local to global impacts: Focus on waste management systems. Resour. Conserv. Recycl. X 2019, 2, 100005. [CrossRef]

55. Iodice, S.; Garbarino, E.; Cerreta, M.; Tonini, D. Sustainability assessment of Construction and Demolition Waste management applied to an Italian case. Waste Manag. 2021, 128, 83-98. [CrossRef]

56. Stojadinović, Z.; Kovačević, M.; Marinković, D.; Stojadinović, B. Rapid earthquake loss assessment based on machine learning and representative sampling. Earthq. Spectra 2021, 1-26. [CrossRef]

57. Tirth, V.; Singh, R.K.; Islam, S.; Badruddin, I.A.; Abdullah, R.A.B.; AlGahtani, A.; Mahmoud, E.R.; Arabi, A.; Shukla, N.K.; Gupta, P. Kharif Crops Selection for Sustainable Farming Practices in the Rajasthan-India Using Multiple Attribute-Based Decision-Making. Agronomy 2020, 10, 536. [CrossRef]

58. Saaty, T.L. How to make a decission: The Analytical Hierarchy Process. Eur. J. Oper. Res. 1990, 48, 9-26. [CrossRef]

59. Maleš, I. Guidelines on Circular Economy for the Countries of the Western Balkans and Turkey. Brussels, 2020. Available online: https:/ / eeb.org/library/guidelines-on-the-circular-economy-for-western-balkan-countries-and-turkey/ (accessed on 1 December 2021).

60. The Confederation of European Waste-to-Energy (CEWEP). Landfill Taxes and Bans. Overvew. 2021. Available online: https: / / www.cewep.eu/landfill-taxes-and-bans / (accessed on 6 September 2021).

61. Muchová, L.; Eder, P. End-of-Waste Criteria for Iron and Steel Scrap: Technical Proposals. EUR 24397 EN; Publications Office of the European Union: Luxembourg, 2010.

62. Villanueva, A.; Eder, P. End-of-Waste Criteria for Glass Cullet: Technical Proposals. EUR 25220 EN; Publications Office of the European Union: Luxembourg, 2011.

63. Muchova, L.; Eder, P.; Villanueva, A. End-of-Waste Criteria for Aluminium and Aluminium Alloy Scrap. Technical Proposals. EUR 24396; Publications Office of the European Union: Luxembourg, 2011.

64. Wu, Z.; Yu, A.T.; Poon, C.S. Promoting effective construction and demolition waste management towards sustainable development: A case study of Hong Kong. Sustain. Dev. 2020, 28, 1713-1724. [CrossRef]

65. United Nations Climate Change. Paris Agreement-Status of Ratification / UNFCCC. Available online: https://unfccc.int/ process/the-paris-agreement/status-of-ratification (accessed on 2 November 2021).

66. The World Bank. Land Area (sq. km) IData. Available online: https://data.worldbank.org/indicator/AG.LND.TOTL.K2 (accessed on 2 November 2021).

67. The World Bank. Population, Total. Available online: https://data.worldbank.org/indicator/SP.POP.TOTL (accessed on 1 November 2021). 
68. IEE Project TABULA. Typology Approach for Building Stock Energy Assessment. Available online: https://episcope.eu/ieeproject/tabula/ (accessed on 1 November 2021).

69. Sandberg, N.H.; Sartori, I.; Heidrich, O.; Dawson, R.; Dascalaki, E.; Dimitriou, S.; Vimm-R, T.; Filippidou, F.; Stegnar, G.; Zavrl, M.Š; et al. Dynamic building stock modelling: Application to 11 European countries to support the energy efficiency and retrofit ambitions of the EU. Energy Build. 2016, 132, 26-38. [CrossRef] 